\title{
Determinants of cancer screening awareness and participation among Indonesian women
}

Sumadi L. Anwarr ${ }^{1,2}$, Gindo Tampubolon ${ }^{3}$, Mieke Van Hemelrijck ${ }^{4}$, Susanna H. Hutajulu', Johnathan Watkins², Wahyu Wulaningsih ${ }^{2,6^{*}}$ (D) and for the PILAR Research Network

\begin{abstract}
Background: Cancer screening awareness and participation may be lower in low- and middle-income countries that lack established national screening programmes compared with those that do. We evaluated potential determinants of awareness about and participation in breast and cervical cancer screening, and breast selfexamination (BSE) in women using survey data from Indonesia.

Methods: From the fifth Indonesian Family Life Survey (2014-2015), a total of 5397 women aged 40 and older without any history of cancer who responded to questionnaires concerning Pap smears, mammography, and BSE were included. Multilevel modelling was used to assess potential determinants in relation to awareness about Pap smears and mammography, and participation in Pap smears and BSE practice. Multivariable analyses were performed to identify independent predictors of cancer screening.

Results: Of the 5397 respondents, 1058 (20\%) women were aware of Pap smears, of which 297 had never had the procedure. Only 251 (5\%) participants were aware of mammography. A total of 605 (12\%) of women reported they performed BSE. Higher education and household expenditure were consistently associated with higher odds of awareness about Pap smears and mammography (e.g. odds ratio [OR] of being aware of Pap smear and mammography: 7.82 (95\% Cl: 6.30-9.70) and 7.70 (6.19-9.58), respectively, for high school graduates compared to women with less educational attainment in the multivariable models), and participation in Pap smears and BSE. We also identified enabling factors linked with greater cancer screening awareness and participation, including health insurance, shorter distance to health services, and social participation.
\end{abstract}

Conclusion: There are socioeconomic disparities in cancer screening awareness and participation among Indonesian women. Our findings may help inform targeted health promotion and screening for cancer in the presence of limited resources.

Keywords: Breast cancer, Screening, Cervical cancer, Pap smears, Breast self-examination

\section{Background}

The overall burden of cancer has been increasing in developing countries [1]. The World Health Organization (WHO) International Agency for Research on Cancer (IARC) estimated that there will be up to 21.7 million new cancer cases and 13 million cancer-related deaths in

\footnotetext{
* Correspondence: w.wulaningsih@ucl.ac.uk

${ }^{2}$ PILAR Research and Education, 20 Station Road, Cambridge CB1 2JD, UK ${ }^{6} \mathrm{MRC}$ Unit for Lifelong Health and Ageing, University College London, Place London WC1B 5JU, Bedford 33, UK

Full list of author information is available at the end of the article
}

2030 , with $70 \%$ of those cases in low- to middle-income countries (LMICs) [2-4]. Although cancer mortality rates have declined in high-income countries, LMICs have seen elevated cancer-related mortality rates [5], owing to a lack of cancer prevention and screening programmes and limited resources to treat cancer $[4,6]$.

In LMICs such as Indonesia, cancers are mostly diagnosed at an advanced stage, in which curative treatment is often no longer possible [7]. For female cancers, breast and cervical cancers remain the leading causes of cancer mortality in Indonesia (21\% and $10 \%$, respectively) [5]. 
Yet, affordable cervical cancer screening is only available in eight of 34 provinces in Indonesia, $[5,8]$ with low awareness and uptake of breast and cervical cancer screening $[5,8,9]$. The low uptake may be attributable to a range of barriers including a lack of knowledge about cancer prevention as well as widespread misconceptions and fears about cancer and its treatment $[9,10]$ also further contribute to the late presentation of disease [11]. In addition, there are often inequalities in the distribution of healthcare workers throughout the country, resulting in inequalities in healthcare access especially between urban and rural areas [12]. Nonetheless, the extent of inequalities in cancer screening awareness and participation in LMICs, such as Indonesia, is often unclear. Additionally, breast self-examination (BSE) as a tool to screen for breast cancer is common in these countries, although there is evidence to suggest that this technique lacks effectiveness [13].

We performed a cross-sectional study of 5397 cancerfree Indonesian women aged 40 and older, the target group for breast and cervical cancer screening based on American Cancer Society Guidelines [14]. We used multilevel regression analyses to identify potential determinants of cervical and breast cancer screening awareness and participation to gain further insight into predisposing, enabling, and need factors which could potentially inform targeted prevention programmes in lowresource settings.

\section{Methods}

\section{Study population}

The Indonesian Family Life Survey (IFLS) is a longitudinal household survey in Indonesia containing information from questionnaires, as well as physical and laboratory examinations. Data were collected at individual, household, and community levels. The first IFLS (IFLS1) used a stratified sampling scheme based on provinces and urban/rural location. For costeffectiveness, 14 of the 27 provinces that existed at the time IFLS1 was conducted were excluded [15]. The resulting sample included 13 of Indonesia's 27 provinces, containing $83 \%$ of the population: four provinces on Sumatra (North Sumatra, West Sumatra, South Sumatra, and Lampung), all five of the Javanese provinces (DKI Jakarta, West Java, Central Java, DI Yogyakarta, and East Java), and four provinces covering the remaining major island groups (Bali, West Nusa Tenggara, South Kalimantan, and South Sulawesi). Within each province, enumeration areas (EAs) were randomly chosen from a nationally representative sample frame used in a socioeconomic survey of about 60,000 households in 1993 [15]. Within a selected EA, households were randomly selected. Interviews were carried out with the household head and the spouse, and up to 4 randomly selected other household members as interviewing all members of the household would have been too costly. All members of the original household were followed up through four subsequent IFLS waves. The present study was based on the fifth wave of IFLS (IFLS5), conducted in 2014-2015. Both original and split-off households were tracked in the IFLS5, resulting in a 76\% re-contact rate (including death) for the original IFLS1 household members, and $82 \%$ for IFLS1 main respondents. From the IFLS5, we included a total of 5397 women aged 40 and older without a self-reported history of cancer who responded to the questions on Pap smears, mammography, and BSE (Additional file 1: Fig. S1).

\section{Cancer screening participation and behaviour}

The outcomes of the present study measured awareness of Pap smears and mammography, and participation in Pap smears and BSE practice. All responses were selfreported and dichotomous (yes, no). First, during the interview, respondents were asked if they had ever heard of a Pap smear. Those who responded positively to this question were further asked whether they had ever received a Pap smear in their life, and, if so, when. Participants were also asked whether they had ever heard about mammography, and those who responded positively were asked whether they had ever received a mammography in the past year. All study participants were asked how many times they had performed BSE in the past year, and we further dichotomised them into those who had performed BSE and who had not.

\section{Potential determinants of screening}

The Anderson model of healthcare-use behaviour [16] was used to identify potential determinants of cancer screening awareness and participation. This model includes three domains: predisposing, enabling, and need factors, which interact in determining one's healthrelated behaviour. From IFLS5 (Fig. 1), predisposing sociodemographic and lifestyle characteristics of the patients were collected including age, ethnicity, urban or rural residence, marital status, education, monthly household expenditure, smoking status, physical activity and personality traits. Ethnicity was categorised into Javanese, which comprises the majority of Indonesians, and non-Javanese. Education was categorised based on the highest level (less than high school, high school, higher education). Household expenditure was calculated based on the total of food, non-food, and education expenditure [17]. Smoking history was used to classify individuals into current, former, and never smokers. Participants were defined as vigorously active if they reported participating in more than two vigorous physical activities in the past week for at least $10 \mathrm{~min}$ each, [18] moderately active if they participated more than 4 times 


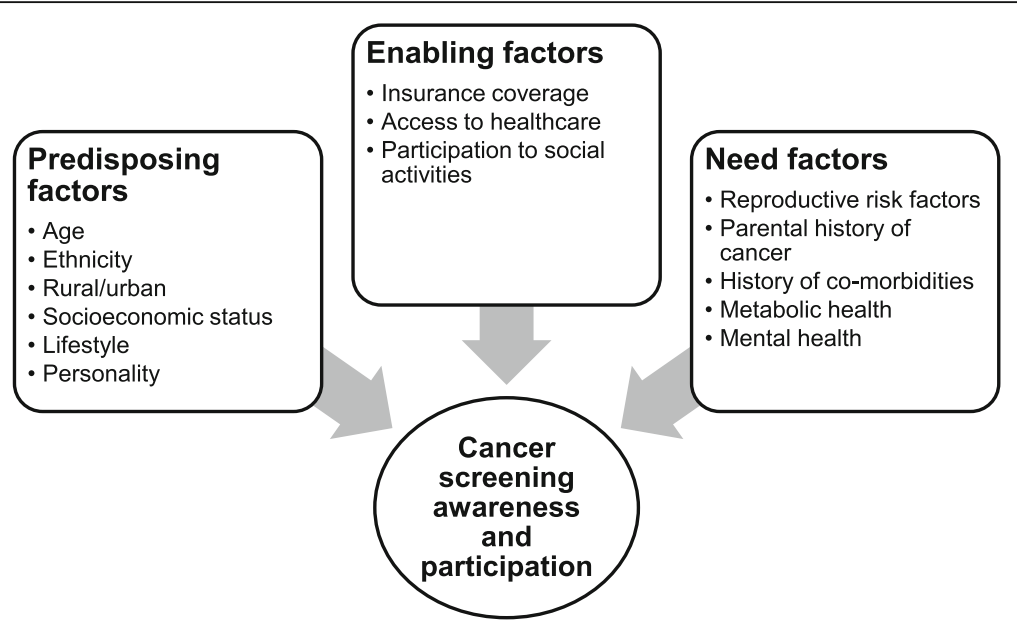

Fig. 1 Potential determinants of cancer screening awareness and participation in IFLS5 based on the Anderson model of health behaviour

in the past week in moderate to vigorous physical activities of which no more than two could be considered vigorous. Lightly active was defined as participating in any activities or walking at least 30 min each time, for more than 2 times in the past week but did not meet the description of vigorously or moderately active. Those who reported no moderate or vigorous physical activity and walked fewer than 3 times a week were categorised as sedentary. Personality traits were assessed with a short (15-item) Big Five Inventory (BFI-15) questionnaire [19], with scores ranging from 1 to 5 for openness, conscientiousness, extroversion, agreeableness, and neuroticism.

Enabling factors identified in the population included health insurance ownership and travel distance in minutes to the nearest healthcare centre, and participation in any social activities within the past year. On 1 January 2014, the Indonesian government launched a compulsory national health insurance,which covers Pap smears [20], although this scheme has yet to cover mammography. However, unequal healthcare access issues were reported within the first year of the scheme being implemented (2014-2015) [21], which is the period in which the present study took place. Therefore, we took into account self-reported insurance coverage in our analysis. Factors representing needs for cancer screening included information on reproductive factors: menopausal status, age at menarche, co-morbidities, parental history of cancer death, and body mass index (BMI) calculated from measured weight and height during physical examination. Co-morbidities were assessed as a comorbidity score similar to the Charlson co-morbidity index, where each co-morbid condition available (hypertension, diabetes, asthma, heart disease, liver disease, stroke, cancer, arthritis, kidney disease, stomach or digestive disease, and memory-related disease) contributed one point to the composite index with additional points given for older age. Finally, to assess the role of mental health, depression was measured with a short version (10-item) of the Center for Epidemiologic Studies Depression Scale (CES-D), [15] and a cut-off of 8 was used for a screening of depressive symptoms [19].

\section{Statistical analysis}

We analysed the association between each determinant with awareness of Pap smears, awareness of mammography, ever-Pap smear, and performed BSE. We did not assess use of mammography as an outcome given the small number of participants with a positive response. To take into account the IFLS sampling design, we performed multilevel logistic regression analyses to obtain odds ratios (ORs) and their 95\% CI for associations between each determinant and outcome. Community clustering was used as a random effect in a two-level multivariable model. Household clustering was not used in the multilevel model due to there being an inadequate number of participants for generating meaningful statistical results for a number of factors. However, where possible, we compared models using both community and household clustering with models using only community clustering with analysis of co-variance, and no difference was observed between these models $(P>0.05)$. Univariable analyses were conducted for all potential determinants of cancer screening awareness and practice. These factors comprised different components of the Anderson model [16], ranging from predisposing factors such as sociodemographic characteristics (e.g. marital status, education, income), enabling factors, which included healthcare access. We additionally included comorbid conditions (e.g. diabetes, obesity as measured by BMI) given the evidence linking comorbidity to cervical and breast cancer screening participation in Western 
populations [22]. Multivariable analyses were further carried out and included factors which showed significant associations with cancer awareness or participation in the univariable models. We performed a sensitivity analysis by grouping participants into those who had performed BSE more than once and those who had. The dataset was prepared with SAS release 9.3 (SAS Institute, Cary, NC). Logistic regression with multilevel modelling was performed with the lme4 package in $\mathrm{R}$ version 3.3.2 ( $\mathrm{R}$ Foundation for Statistical Computing, Vienna, Austria).

\section{Results}

Characteristics of the study participants $(N=5397)$ are presented in Table 1. The mean age of participants was 52.9 years. The majority of women were of Javanese ethnicity, married, lived in urban areas, and had not completed high school. Nearly a quarter $(23 \%)$ of women had three or more co-morbidities, and a similar proportion were overweight $\left(\mathrm{BMI} \geq 25 \mathrm{~kg} / \mathrm{m}^{2}\right)$. Only 1058 (20\%) women were aware of Pap smears and 297 among them had undergone at least one Pap smear in their lifetime. A total of 251 (5\%) participants were aware of mammography, among which five had had a mammogram in the previous year. Twelve percent of women reported they had performed BSE in the past year. We additionally present the demographic characteristics of women who did not respond to questions on cancer screening (Additional file 1: Table S1), which comprised $9.6 \%$ of women aged 40 and older. Compared to women who provided a response to cancer screening, nonresponders were in average older, less educated, had lower household expenditure, and more likely to be non-Javanese or unmarried.

\section{Determinants of awareness of pap smears}

Table 2 shows potential determinants of awareness of Pap smears identified through univariable regressions and grouped according to the Anderson model. Some categories, for instance education levels, were merged in the analysis due to the limited numbers of participants. In the analysis, age, ethnicity, urban residence, marital status, education level, household expenditure, physical activity, openness, extroversion, agreeableness, neuroticism, insurance, distance to healthcare providers, menopausal status, age at menarche, comorbidity score, parental deaths of cancer, overweight, and CESD were associated with awareness of Pap smears. In the multivariable analysis (Table 4), being Javanese (OR: 1.91, 95\% CI: 1.52-2.40), living in urban area (OR: 4.28, 3.225.67), graduating high school (OR: 7.82, 6.30-9.70), greater household expenditure (OR: 2.31, 1.91-2.80), physical activity (OR: 1.54, 1.25-1.91), agreeable (1.63, 1.30-2.03) and neuroticism traits (OR: 1.23, 1.02-1.49), having insurance (OR: 2.05, 1.69-2.49), and participating
Table 1 Characteristics of study participants $(N=5397)$

\begin{tabular}{|c|c|c|}
\hline \multirow{2}{*}{$\begin{array}{l}\text { Potential determinants } \\
\text { Predisposing }\end{array}$} & \multicolumn{2}{|l|}{ N (\%) } \\
\hline & & \\
\hline \multirow[t]{2}{*}{ Age } & $40-60$ & $4098(75.93)$ \\
\hline & $\geq 60$ & $1299(24.07)$ \\
\hline \multirow[t]{2}{*}{ Ethnicity } & Not Javanese & $2900(43.73)$ \\
\hline & Javanese & $2497(46.27)$ \\
\hline \multirow[t]{2}{*}{ Residence } & Rural & $2339(43.34)$ \\
\hline & Urban & $3058(56.66)$ \\
\hline \multirow[t]{2}{*}{ Marital status } & Not married & $1423(26.37)$ \\
\hline & Married & $3974(73.63)$ \\
\hline \multirow[t]{3}{*}{ Education } & Less than high school & $3534(65.48)$ \\
\hline & High school & $1529(28.33)$ \\
\hline & Higher education & $334(6.19)$ \\
\hline \multirow[t]{2}{*}{ Monthly household expenditure } & Tertile $1-2$ & $3561(65.98)$ \\
\hline & Tertile 3 & $1836(34.02)$ \\
\hline \multirow[t]{3}{*}{ Tobacco smoking } & Never & $5157(95.55)$ \\
\hline & Former & $63(1.17)$ \\
\hline & Ever & $177(3.28)$ \\
\hline \multirow[t]{4}{*}{ Physical activity } & Sedentary & $1627(30.15)$ \\
\hline & Lightly active & $1793(33.22)$ \\
\hline & Moderately active & $1460(27.05)$ \\
\hline & Vigorously active & $517(9.58)$ \\
\hline \multirow[t]{2}{*}{ Openness } & $<4$ & $4715(87.36)$ \\
\hline & $\geq 4$ & $682(12.64)$ \\
\hline \multirow[t]{2}{*}{ Conscientiousness } & $<4$ & $4690(86.90)$ \\
\hline & $\geq 4$ & $707(13.10)$ \\
\hline \multirow[t]{2}{*}{ Extroversion } & $<4$ & $3203(59.35)$ \\
\hline & $\geq 4$ & $2194(40.65)$ \\
\hline \multirow[t]{2}{*}{ Agreeableness } & $<4$ & $1771(32.81)$ \\
\hline & $\geq 4$ & $3626(67.19)$ \\
\hline \multirow[t]{2}{*}{ Neuroticism } & $<4$ & $3191(59.13)$ \\
\hline & $\geq 4$ & $2206(40.87)$ \\
\hline \multicolumn{3}{|l|}{ Enabling } \\
\hline \multirow[t]{2}{*}{ Insured } & No & $2754(51.03)$ \\
\hline & Yes & $2643(48.97)$ \\
\hline \multirow[t]{2}{*}{ Travel time } & $<10 \min$ & $4503(83.44)$ \\
\hline & $\geq 10 \min$ & $894(16.56)$ \\
\hline \multirow[t]{2}{*}{ Participating in social activities } & No & $806(14.93)$ \\
\hline & Yes & $4591(85.07)$ \\
\hline \multicolumn{3}{|l|}{ Need } \\
\hline \multirow[t]{2}{*}{ Menopausal status } & Premenopausal & $2300(42.61)$ \\
\hline & Postmenopausal & $3097(57.38)$ \\
\hline \multirow[t]{2}{*}{ Age at menarche } & $<14$ & $2133(39.52)$ \\
\hline & $\geq 14$ & $3264(60.48)$ \\
\hline
\end{tabular}


Table 1 Characteristics of study participants $(N=5397)$ (Continued)

\begin{tabular}{lll}
\hline Potential determinants & $\mathrm{N}(\%)$ & \\
\hline Co-morbidity score & 0 & $1476(27.35)$ \\
& 1 & $1506(27.90)$ \\
& 2 & $1162(21.53)$ \\
& 3 and more & $1253(23.22)$ \\
Parent died from cancer & No & $5264(97.54)$ \\
& Yes & $133(2.46)$ \\
BMl & $<25 \mathrm{~kg} / \mathrm{m}^{2}$ & $2879(53.34)$ \\
& $\geq 25 \mathrm{~kg} / \mathrm{m}^{2}$ & $2518(46.66)$ \\
CES-D & $<8$ & $5097(94.44)$ \\
& $\geq 8$ & $300(5.66)$ \\
\hline
\end{tabular}

in social activities (OR: 2.12, 1.50-2.98) corresponded to higher likelihood of being aware of Pap smears. As shown in Table 4, a decrease in the odds of Pap smear awareness was shown as the distance to a healthcare provider increased (OR: 0.73, 0.55-0.98) and CESD score (OR: 0.68, 0.55-0.85) in the multivariable model.

\section{Determinants of awareness of mammography}

Similar patterns of associations between potential predictors and awareness of Pap smears were observed for awareness of mammography in the univariable analysis (Table 2). In the multivariable model, we found higher odds of being aware of mammography in women living in urban areas (OR: 4.51, 95\% CI: 3.36-6.06), women who had graduated high school (OR: 7.70, 6.19-9.58), women with higher household expenditure (OR: 2.28, $1.88-2.76$ ), women that do physical activity (OR: 1.54 , $1.24-1.90)$, women who have greater agreeableness (OR: $1.67,1.33-2.09$ ), women with neuroticism traits (OR: $1.24,1.03-2.09$ ), women who have insurance (OR: 2.01, $1.65-2.44)$, and women who participate in social activities (OR: 2.29, 1.62-3.23) (Table 4). Living further from health services (OR: 0.70, 0.52-0.94) and being postmenopausal (OR: $0.79,0.63-0.99)$ were inversely associated with being aware of mammography in the multivariable model.

\section{Determinants of pap smear participation}

We assessed factors associated with participation in Pap smears (Table 3), and only found education level, household expenditure, insurance, menopausal status and comorbidity score to be associated with participation in Pap smears in the univariable analysis. In the multivariable models, women were more likely to have had a Pap smear if they had graduated high school (OR: 1.58, 95\% CI: 1.04-2.41), had higher household expenditure (OR: 1.94, 1.40-2.69), had insurance (1.57 (1.12-2.22), and had two or more comorbidities $(1.45,1.01-2.08)$ (Table 4).

\section{Determinants of BSE practice}

A number of factors were associated with having performed BSE in the past year in univariable analyses (Table 3). In the multivariable analysis, those associated with higher odds of practicing BSE were living in urban areas (OR: 1.97, 95\% CI: 1.54-2.51), had higher education (OR: 4.26, 3.39-5.36), had higher household expenditure (OR: 1.68, 1.38-2.05), had higher agreeable traits (OR: 1.61, 1.26-2.05), had insurance (OR: 1.44, 1.18-1.76), and engaged in social activities (OR: $2.00,1.38-2.88$ ) (Table 4). A borderline association was shown for physical activity (OR: 1.24, 95\% CI: 1.001.54) and having menarche at age 14 or older (OR: 0.95 , $0.90-1.00$ compared to at younger ages) in the multivariable model.

\section{Sensitivity analyses}

Results were also similar when we used BSE at least twice $(N=723)$ instead of once in the past year $(N=796)$ to define women who practiced BSE as the outcome, but this did not alter our findings (data not shown).

\section{Discussion}

Our study identified predisposing, enabling, and need factors associated with awareness of cancer screening and participation in Indonesian women. Most persistent associations were observed for socio-economic determinants, particularly higher education, household expenditure, and ownership of health insurance, which were associated with higher awareness of Pap smears and mammography, and higher odds of participating in Pap smears and BSE. A similar positive association was observed for social activity participation with awareness of Pap smears and BSE practice, whereas distance to nearest health centres was inversely associated with awareness of Pap smears and mammography. Our findings also uncovered associations between personality traits, and Pap-smear awareness and participation and BSE practice which remained when taking into account other determinants.

Despite the increasing cancer burden, most LMICs are yet to publish national guidelines for screening and early detection of breast and cervical cancers [5, 23]. In other LMICs in which national cancer screening programmes have been introduced, such as those in the Middle East and North Africa where screening ranges from $2 \%$ to $70 \%$ of the at-risk population, improving participation rates remains a challenge [24]. In Sub-Saharan Africa, fewer than $5 \%$ of women at risk are estimated to have been screened for cervical cancer $[25,26]$. Populationbased cervical cancer screening programmes have been in place for more than 10 years in India, however, participation rates are also relatively low [27, 28]. The 
Table 2 Univariable associations of potential determinants with cancer screening awareness among women 40 years and older without known history of any cancer

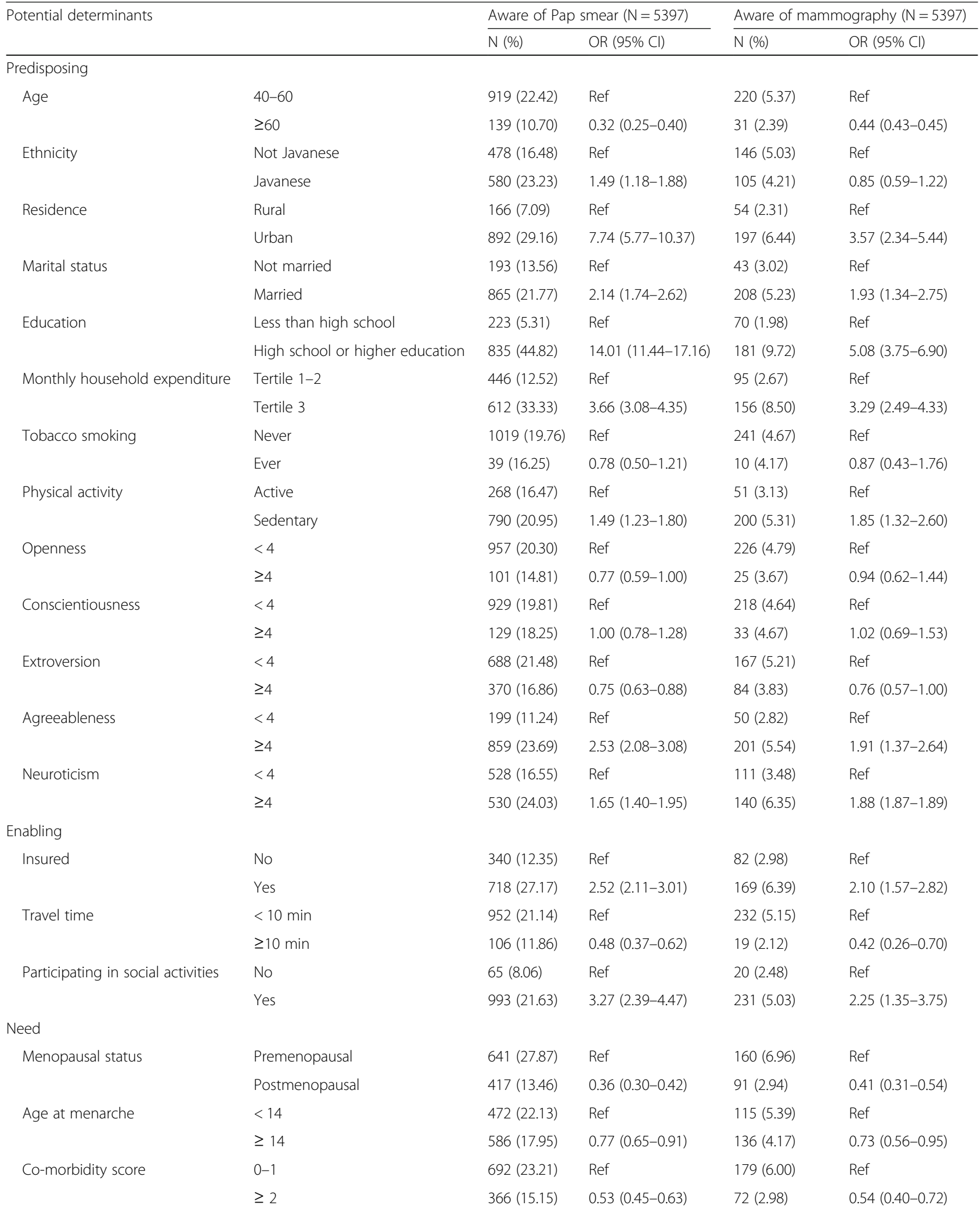


Table 2 Univariable associations of potential determinants with cancer screening awareness among women 40 years and older without known history of any cancer (Continued)

\begin{tabular}{|c|c|c|c|c|c|}
\hline \multirow[t]{2}{*}{ Potential determinants } & & \multicolumn{2}{|c|}{ Aware of Pap smear $(N=5397)$} & \multicolumn{2}{|c|}{ Aware of mammography $(N=5397)$} \\
\hline & & $\mathrm{N}(\%)$ & OR $(95 \% \mathrm{Cl})$ & $\mathrm{N}(\%)$ & OR $(95 \% \mathrm{Cl})$ \\
\hline \multirow[t]{2}{*}{ Parent died from cancer } & No & $1009(19.17)$ & Ref & $238(4.52)$ & Ref \\
\hline & Yes & $49(36.84)$ & $2.58(1.62-4.11)$ & $13(9.77)$ & $2.25(1.15-4.41)$ \\
\hline \multirow[t]{2}{*}{ BMI } & $<25 \mathrm{~kg} / \mathrm{m}^{2}$ & $457(15.87)$ & Ref & $121(4.20)$ & Ref \\
\hline & $\geq 25 \mathrm{~kg} / \mathrm{m}^{2}$ & $601(23.87)$ & $1.49(1.26-1.76)$ & $130(5.12)$ & $1.12(0.85-1.48)$ \\
\hline \multirow[t]{2}{*}{ CES-D } & $<8$ & $820(21.42)$ & Ref & $190(4.96)$ & Ref \\
\hline & $\geq 8$ & $238(15.18)$ & $0.73(0.60-0.88)$ & 61 (3.89) & $0.86(0.63-1.17)$ \\
\hline
\end{tabular}

Indonesian Ministry of Health has recently released new recommendations for preventive measures against cervical and breast cancer (PERMENKES RI No.34/2015) [29]. Approximately 34.5 million Indonesian women are expected to participate in this breast and cervical cancer screening program [29]. According to government recommendations, health promotion should be conducted through public events, media, religious communities, and other civic society channels. Preventive measures include mass screening, mainly for cervical cancer using visual inspection with acetic acid, should be organised as public events. Women in the target age groups may also request examinations for early detection at healthcare facilities. However, no formal invitation for screening is sent to individuals, and there is a lack of clear guidelines regarding the use of mammography. In 2015, only 904,099 (4.94\%) women had completed screening and early detection examination for breast and cervical cancer, a similar figure to that observed in this study. The target coverage, however, is $50 \%$ by 2019 [29].

Most women in developing countries seek medical care after they develop symptoms. For instance, more than $70 \%$ of cervical cancer patients in developing countries visited a hospital once their cancer had already infiltrated the parametrium $[30,31]$. A population based-study conducted in Indonesia demonstrated that implementation of small-scale cervical cancer screening project reached only $24 \%$ of females in the target group despite the implementation of a mobile screening service to reach more inaccessible areas [32]. We did not find any report evaluating existing programmes or intervention approaches for breast cancer screening. However, it is worth noting that mammography and breast ultrasonography are currently only covered by the national universal health insurance in particular health facilities, which may explain the low cancer screening awareness and participation more generally.

Only a few studies have addressed the role of mental health and personality traits in cancer screening awareness and participation in LMICs [33, 34]. In our study, a higher CES-D score, which is linked to symptoms of depression, was associated with low awareness of Pap smears, but higher odds of BSE practice. This corroborates previous findings linking stress and depression, which are generally more common in individuals of low SES [35], with health-related behaviours [34]. Community support might be required to achieve the desirable level of awareness and participation in cancer screening, especially in women with psychiatric comorbidities. We found associations between higher agreeableness and higher awareness of Pap smears and BSE practice, whereas higher neuroticism was linked with higher awareness of cancer screening. Using a similar approach, two studies also reported associations between personality traits and cancer-related health behaviours, with higher conscientiousness associated with higher participation in bowel and prostate cancer screenings [36, 37]. The positive correlation between conscientiousness and cancer screening awareness did not reach statistical significance in our study. However, our findings support the use of personality-tailored approaches to raise awareness of and participation in cancer screening among women.

As shown in our study and previous ones, sociodemographic determinants including household socioeconomic status, ethnicity [38], rural residence, health expenditure, and healthcare access [38] are associated with participation in breast and cervical cancer screening [39]. In addition to these factors, we demonstrated that existing comorbidities were associated with awareness of and participation in screening of breast and cervical cancers. These findings may indicate a complex relationship between health and sociodemographic factors in determining population awareness of, and participation in cancer screening. Therefore, multiple health policies are required to improve the public's awareness of screening and other initatives as well as the healthcare system's ability to deliver these initiatives. Interventions may also be needed to advance the skills of primary caregivers for detecting breast and cervical cancer, to promote prompt referrals, to strengthen the system's capacity for diagnostic imaging, cytology, and histopathology, and to deliver multimodal breast and cervical cancer treatment. Moreover, an 
Table 3 Univariable associations of potential determinants with cancer screening practice among women 40 years and older without known history of any cancer

\begin{tabular}{|c|c|c|c|c|c|}
\hline \multirow[t]{2}{*}{ Potential determinants } & & \multicolumn{2}{|c|}{ Ever Pap smear $(N=1058)$} & \multicolumn{2}{|c|}{ Performed BSE $(\mathrm{N}=5397)$} \\
\hline & & $\mathrm{N}(\%)$ & $\mathrm{OR}(95 \mathrm{Cl})$ & $\mathrm{N}(\%)$ & OR (95 Cl) \\
\hline \multicolumn{6}{|l|}{ Predisposing } \\
\hline \multirow[t]{2}{*}{ Age } & $40-60$ & $254(27.64)$ & Ref & $538(13.13)$ & Ref \\
\hline & $\geq 60$ & $43(30.94)$ & $1.06(0.55-2.03)$ & $67(5.16)$ & $0.33(0.25-0.43)$ \\
\hline \multirow[t]{2}{*}{ Ethnicity } & Not Javanese & $133(27.82)$ & Ref & $302(10.41)$ & Ref \\
\hline & Javanese & $164(28.28)$ & $0.58(0.72-1.33)$ & $303(12.13)$ & $1.20(0.96-1.51)$ \\
\hline \multirow[t]{2}{*}{ Residence } & Rural & $50(30.12)$ & Ref & $129(5.52)$ & Ref \\
\hline & Urban & $247(27.69)$ & $0.85(0.56-1.28)$ & $476(15.56)$ & $3.54(2.74-4.58)$ \\
\hline \multirow[t]{2}{*}{ Marital status } & Not married & $52(26.94)$ & Ref & $99(6.96)$ & Ref \\
\hline & Married & $245(28.32)$ & $1.10(0.76-1.60)$ & $506(12.73)$ & $2.06(1.62-2.61)$ \\
\hline \multirow[t]{2}{*}{ Education } & Less than high school & $48(21.52)$ & Ref & $141(3.99)$ & Ref \\
\hline & High school or higher education & $249(29.82)$ & $1.70(1.16-2.50)$ & $464(24.91)$ & $8.24(6.67-10.18)$ \\
\hline \multirow[t]{2}{*}{ Monthly household expenditure } & Tertile 1-2 & $92(20.63)$ & Ref & $265(7.44)$ & $1.70(1.54-1.88)$ \\
\hline & Tertile 3 & $205(33.50)$ & $2.08(2.07-2.09)$ & $340(18.52)$ & \\
\hline \multirow[t]{2}{*}{ Tobacco smoking } & Never & $286(28.07)$ & Ref & $580(11.25)$ & Ref \\
\hline & Ever & $11(28.21)$ & $1.06(0.50-2.26)$ & $25(10.42)$ & $0.95(0.60-1.51)$ \\
\hline \multirow[t]{2}{*}{ Physical activity } & Active & $72(26.87)$ & Ref & $157(9.64)$ & Ref \\
\hline & Sedentary & $225(28.48)$ & $1.12(0.80-1.56)$ & $448(11.88)$ & $1.30(1.06-1.60)$ \\
\hline \multirow[t]{2}{*}{ Openness } & $<4$ & $272(28.42)$ & Ref & $544(11.54)$ & Ref \\
\hline & $\geq 4$ & $25(24.75)$ & $0.89(0.55-1.45)$ & $61(8.94)$ & $0.79(0.59-1.07)$ \\
\hline \multirow[t]{2}{*}{ Conscientiousness } & $<4$ & $264(28.42)$ & Ref & $531(11.32)$ & Ref \\
\hline & $\geq 4$ & $33(25.58)$ & $0.83(0.53-1.29)$ & $74(10.47)$ & $0.95(0.72-1.25)$ \\
\hline \multirow[t]{2}{*}{ Extroversion } & $<4$ & 199 (28.92) & Ref & $400(12.49)$ & Ref \\
\hline & $\geq 4$ & 98 (26.49) & $0.96(0.72-1.30)$ & $205(9.34)$ & $0.74(0.61-0.90)$ \\
\hline \multirow[t]{2}{*}{ Agreeableness } & $<4$ & $59(29.65)$ & Ref & $107(6.04)$ & Ref \\
\hline & $\geq 4$ & $238(27.71)$ & $0.97(0.69-1.39)$ & 498 (13.73) & $2.48(1.98-3.11)$ \\
\hline \multirow[t]{2}{*}{ Neuroticism } & $<4$ & $135(25.57)$ & Ref & $294(9.21)$ & Ref \\
\hline & $\geq 4$ & $162(20.57)$ & $1.31(0.99-1.74)$ & $311(14.09$ & 1.61 (1.34-1.93) \\
\hline \multicolumn{6}{|l|}{ Enabling } \\
\hline \multirow[t]{2}{*}{ Insured } & No & $76(22.35)$ & Ref & $217(7.87)$ & Ref \\
\hline & Yes & $221(30.78)$ & $1.70(1.23-2.37)$ & $388(14.68)$ & $1.97(1.63-2.39)$ \\
\hline \multirow[t]{2}{*}{ Travel time } & $<10 \min$ & $275(28.87)$ & Ref & $545(12.10)$ & Ref \\
\hline & $\geq 10 \mathrm{~min}$ & $22(20.75)$ & $0.61(0.36-1.02)$ & $60(6.71)$ & $0.52(0.39-0.70)$ \\
\hline \multirow[t]{2}{*}{ Participating in social activities } & No & $13(20.00)$ & Ref & $38(4.71)$ & Ref \\
\hline & Yes & $284(28.60)$ & $1.56(0.81-3.00)$ & $567(12.35)$ & 2.85 (1.99-4.08) \\
\hline \multicolumn{6}{|l|}{ Need } \\
\hline \multirow[t]{2}{*}{ Menopausal status } & Premenopausal & $163(25.42)$ & Ref & $403(17.52)$ & Ref \\
\hline & Postmenopausal & $134(32.13)$ & $1.38(1.04-1.85)$ & $202(6.52)$ & $0.32(0.26-0.38)$ \\
\hline \multirow[t]{2}{*}{ Age at menarche } & $<14$ & $138(29.24)$ & Ref & $274(12.85)$ & Ref \\
\hline & $\geq 14$ & $159(27.13)$ & $0.87(0.65-1.15)$ & $331(10.14)$ & $0.80(0.66-0.96)$ \\
\hline \multirow[t]{2}{*}{ Co-morbidity score } & $0-1$ & $73(25.29)$ & Ref & $412(13.82)$ & Ref \\
\hline & $\geq 2$ & $58(33.33)$ & $1.58(1.18-2.12)$ & $193(7.99)$ & $0.52(0.43-0.63)$ \\
\hline
\end{tabular}


Table 3 Univariable associations of potential determinants with cancer screening practice among women 40 years and older without known history of any cancer (Continued)

\begin{tabular}{|c|c|c|c|c|c|}
\hline \multirow[t]{2}{*}{ Potential determinants } & & \multicolumn{2}{|c|}{ Ever Pap smear $(N=1058)$} & \multicolumn{2}{|c|}{ Performed BSE $(\mathrm{N}=5397)$} \\
\hline & & $\overline{N(\%)}$ & OR $(95 \mathrm{Cl})$ & $\overline{N(\%)}$ & OR $(95 \mathrm{Cl})$ \\
\hline \multirow[t]{2}{*}{ Parent died from cancer } & No & $281(27.85)$ & Ref & $573(10.89)$ & Ref \\
\hline & Yes & $16(32.65)$ & $1.30(0.68-2.50)$ & $32(24.06)$ & $2.42(1.54-3.83)$ \\
\hline \multirow[t]{2}{*}{ BMI } & $<25 \mathrm{~kg} / \mathrm{m}^{2}$ & $119(26.04)$ & Ref & $264(9.17)$ & Ref \\
\hline & $\geq 25 \mathrm{~kg} / \mathrm{m}^{2}$ & $178(29.62)$ & $1.18(0.89-1.58)$ & $341(13.54)$ & $1.44(1.20-1.74)$ \\
\hline \multirow[t]{2}{*}{ CES-D } & $<8$ & $235(28.66)$ & Ref & $439(11.47)$ & Ref \\
\hline & $\geq 8$ & $62(26.05)$ & $0.91(0.65-1.28)$ & $166(10.59)$ & $0.99(0.81-1.22)$ \\
\hline
\end{tabular}

effective nationwide cancer registry needs to be established to map cancer incidence and to coordinate screening and evaluation efforts.

The main strength of this study lies in the large number of participants, who live in areas covering $83 \%$ of the population in Indonesia in 1993. We were able to account for community clustering and various potential determinants of cancer screening awareness and participation in women. A limitation of this study was that cancer screening awareness only relied on dichotomous responses of questionnaires, without any additional responses allowing for cross-validation and potentially more qualitative work. Additionally, most information was self-reported. However, any misclassification is likely to have been non-differential.

Table 4 Multivariable associations of potential determinants with cancer screening awareness among women 40 years and older without known history of any cancer

\begin{tabular}{|c|c|c|c|c|}
\hline \multirow[t]{2}{*}{ Potential determinants $^{a}$} & \multicolumn{4}{|l|}{ OR $(95 \% \mathrm{Cl})$} \\
\hline & Aware of pap smear & Aware of mammography & Ever pap smear & Performed BSE \\
\hline \multicolumn{5}{|l|}{ Predisposing } \\
\hline Age & $0.72(0.52-0.99)$ & $0.74(0.53-1.01)$ & & $0.82(0.58-1.18)$ \\
\hline Javanese & $1.91(1.52-2.40)$ & & & \\
\hline Urban residence & $4.28(3.22-5.67)$ & $4.51(3.36-6.06)$ & & $1.97(1.54-2.51)$ \\
\hline Married & $1.12(0.88-1.43)$ & $1.13(0.88-1.44)$ & & $1.10(0.85-1.44)$ \\
\hline High school or higher education & $7.82(6.30-9.70)$ & $7.70(6.19-9.58)$ & $1.58(1.04-2.41)$ & $4.26(3.39-5.36)$ \\
\hline Monthly household expenditure - higher tertile & $2.31(1.91-2.80)$ & $2.28(1.88-2.76)$ & $1.94(1.40-2.69)$ & $1.68(1.38-2.05)$ \\
\hline Physically active & $1.54(1.25-1.91)$ & $1.54(1.24-1.90)$ & & $1.24(1.00-1.54)$ \\
\hline Openness $\geq 4$ & $0.90(0.67-1.22)$ & & & \\
\hline Extroversion $\geq 4$ & $0.87(0.71-1.05)$ & $0.83(0.69-1.01)$ & & $0.83(0.68-1.02)$ \\
\hline Agreeableness $\geq 4$ & $1.63(1.30-2.03)$ & $1.67(1.33-2.09)$ & & $1.61(1.26-2.05)$ \\
\hline Neuroticism $\geq 4$ & $1.23(1.02-1.49)$ & $1.24(1.03-2.09)$ & & $1.19(0.98-1.44)$ \\
\hline \multicolumn{5}{|l|}{ Enabling } \\
\hline Have insurance & $2.05(1.69-2.49)$ & $2.01(1.65-2.44)$ & $1.57(1.12-2.22)$ & $1.44(1.18-1.76)$ \\
\hline Travel $\geq 10$ min to health service & $0.73(0.55-0.98)$ & $0.70(0.52-0.94)$ & & $0.76(0.56-1.03)$ \\
\hline Participating in social activities & $2.12(1.50-2.98)$ & $2.29(1.62-3.23)$ & & $2.00(1.38-2.88)$ \\
\hline \multicolumn{5}{|l|}{ Need } \\
\hline Postmenopausal & $0.76(0.61-0.96)$ & $0.79(0.63-0.99)$ & $1.29(0.90-1.83)$ & $0.58(0.56-1.03)$ \\
\hline Age at menarche $\geq 14$ & $0.98(0.93-1.02)$ & $0.98(0.93-1.03)$ & & $0.95(0.90-1.00)$ \\
\hline Co-morbidity score $\geq 2$ & $1.18(0.92-1.50)$ & $1.09(0.86-1.40)$ & $1.45(1.01-2.08)$ & $1.10(0.85-1.41)$ \\
\hline Parent died from cancer & $1.50(0.90-2.50)$ & $1.50(0.89-2.52)$ & & $1.59(0.99-2.54)$ \\
\hline $\mathrm{BMI} \geq 25 \mathrm{~kg} / \mathrm{m}^{2}$ & $1.15(0.95-1.39)$ & & & $1.07(0.89-1.30)$ \\
\hline CES-D $\geq 8$ & $0.68(0.55-0.85)$ & & & \\
\hline
\end{tabular}

${ }^{\mathrm{a}}$ For categorical factors, odds ratios (ORs) were shown for categories displayed in the left-hand column in comparison with the remaining categories as the reference (see Table 2-3) 
We did not use specific cancer questionnaires to measure awareness such as the UK Cancer Awareness Measure [40], since the survey was not originally designed for this particular purpose. Development and validation of a cancer awareness measurement tool that is socioculturally relevant to the Indonesian population is therefore necessary to refine our understanding of the variability in awareness of cancer screening in Indonesia. We were only able to capture mammography use in the past year due to data availability, and this may be a subject of further investigations. It should also be noted that less educated women may have been less familiar with certain medical terminology, although in Indonesia, the terms 'Pap smear' and 'mammography' are commonly used in the primary care settings [29]. However, we still observed associations between other factors and awareness to either Pap smears or mammography when adjusting for educational levels. Spurious correlations may be of concern when performing multiple comparisons as shown in our study. However, we planned our analyses based on a priori models and our results are explained by potential socioeconomic and health-related mechanisms, and are confirmed by findings from other studies. Therefore, the observed association is unlikely to be spurious [41], although a discrepancy with the strength of the true association is possible due to the small number of participants. Women who responded to screening questionnaires may have different characteristics compared to all women aged 40 and older. Furthermore, although IFLS5 covered most respondents from the original IFLS1 survey, there have been rapid demographic changes in Indonesia [42]. These patterns may reduce the generalisability of our findings. However, demographic transition is well-reflected in the study population, such as the greater number of women living in urban areas in IFLS5 as opposed to the majority living in rural areas in 1993 [42]. Furthermore, this cohort effect is unlikely to affect the internal validity of the results. Finally, our analyses were cross-sectional and only imply associations. Untangling causal associations is necessary to identify key modifiable factors that improve or worsen awareness of and participation in cancer screening.

\section{Conclusion}

We identified a number of factors associated with cervical and breast cancer screening awareness and practice in Indonesia. Improvement of enabling factors such as access to healthcare and social participation may help enhance cancer screening in low-resource settings, particularly among subgroups of women who are socio-economically susceptible to a low awareness of cancer screening. The different associations observed with different personality traits support the potential benefit of employing a range of strategies to promote cancer awareness and participation in Indonesia and potentially other LMICs that lack longestablished cancer screening programmes.

\section{Additional file}

Additional file 1: Table S1. Demographic characteristics of women based on response to questions on cancer screening. Figure S1. Selection of study participants from IFLS5. (PDF $312 \mathrm{~kb}$ )

\section{Acknowledgements}

The authors would like to thank Mr. Eric Hookom for reviewing and commenting on the manuscript draft.

\section{Funding}

WW is employed by grants from the UK Medical Research Council [MC_UU_12019/2] and [MC_UU_12019/4]. GT is funded by the UK Medical Research Council [G1001375/1], UK Economic \& Social Research Council [ES/ L001772/1], and EU Horizon 2020 [668648]. Funding for IFLS5 was provided by the National Institute on Aging (NIA), grant 2R01 AG026676-05, the National Institute for Child Health and Human Development (NICHD), grant 2R01 HD050764-05A1 and grants from the World Bank, Indonesia and GRM International, Australia from DFAT, the Department of Foreign Affairs and Trade, Government of Australia. The funding body had no role in the design of the study and collection, analysis, and interpretation of data and in writing the manuscript.

\section{Availability of data and materials}

The dataset is publicly available at the RAND Corporation's website (http:// www.rand.org/labor/FLS/IFLS/ifls5.html).

\section{Authors' contributions}

SLA and WW conceptualised the study. SLA, GT, JW and WW prepared the data used for the analysis. SLA and WW performed the analysis with critical feedback from GT and MVH. All authors interpreted the results of the analysis. SLA wrote the first draft. All authors reviewed and edited the draft and agreed on the final version of the manuscript.

\section{Ethics approval and consent to participate}

The research has been performed in accordance with the Declaration of Helsinki. The IFLS surveys and their procedures were reviewed and approved by the following ethics committees: IRBs (Institutional Review Boards) in the United States (at RAND) and in Indonesia at the Universitas Gadjah Mada (UGM) for IFLS5. Further information about ethical approval is available on RAND website https://www.rand.org/labor/FLS/IFLS.html. Informed consent was obtained from all participants.

\section{Consent for publication}

Not applicable

Competing interests

The authors declare that they have no competing interests.

\section{Publisher's Note}

Springer Nature remains neutral with regard to jurisdictional claims in published maps and institutional affiliations.

\section{Author details}

${ }^{1}$ Division of Surgical Oncology Department of Surgery, Faculty of Medicine Universitas Gadjah Mada, Yogyakarta 55281, Indonesia. ${ }^{2}$ PILAR Research and Education, 20 Station Road, Cambridge CB1 2JD, UK. ${ }^{3}$ Cathie Marsh Institute for Social Research, University of Manchester, M13 9PL, Manchester, UK. ${ }^{4}$ Translational Oncology and Urology Research, King's College London, London SE1 9RT, UK. ${ }^{5}$ Division of Medical Haematology and Oncology Department of Internal Medicine, Faculty of Medicine Universitas Gadjah Mada, Yogyakarta 55281, Indonesia. ${ }^{6}$ MRC Unit for Lifelong Health and Ageing, University College London, Place London WC1B 5JU, Bedford 33, UK. 


\section{Received: 19 June 2017 Accepted: 12 February 2018} Published online: 06 March 2018

\section{References}

1. Ferlay J, Soerjomataram I, Dikshit R, Eser S, Mathers C, Rebelo M, et al. Cancer incidence and mortality worldwide: sources, methods and major patterns in GLOBOCAN 2012. Int J Cancer. 2015;136:E359-86.

2. Torre LA, Bray F, Siegel RL, Ferlay J, Lortet-tieulent J, Jemal A. Global cancer statistics, 2012. CA a cancer J Clin. 2015:65:87-108.

3. Global Burden of Disease Cancer Collaboration, Fitzmaurice C, Dicker D, Pain A, Hamavid H, Moradi-Lakeh M, et al. The Global Burden of Cancer 2013. JAMA Oncol. 2015;1:505-27.

4. De Souza JA, Hunt B, Asirwa FC, Adebamowo C, Lopes G. Global health equity: cancer care outcome disparities in high-, middle-, and low-income countries. J Clin Oncol. 2016:6-13.

5. World Health Organization. Cancer Country Profile: Indonesia. Cancer Country. Profile. 2014;50:1-4

6. DeSantis CE, Bray F, Ferlay J, Lortet-Tieulent J, Anderson BO, Jemal A International variation in female breast cancer incidence and mortality rates. Cancer Epidemiol Biomarkers Prev. 2015:24:1495-506.

7. Camacho R, Sepúlveda C, Neves D, Piñeros M, Villanueva M, Dangou J-M, et al. Cancer control capacity in 50 low- and middle-income countries. Glob Public Heal An Int J Res Policy Pract. 2015;10:1017-31.

8. Vet JNI, Kooijman JL, Henderson FC, Aziz FM, Purwoto G, Susanto H, et al. Single-visit approach of cervical cancer screening: see and treat in Indonesia. Br J Cancer. 2012:107:772-7.

9. Iskandarsyah A, de Klerk C, Suardi DR, Soemitro MP, Sadarjoen SS, Passchier J. Psychosocial and cultural reasons for delay in seeking help and nonadherence to treatment in Indonesian women with breast cancer: a qualitative study. Health Psychol. 2014;33:214-21.

10. Price AJ, Ndom P, Atenguena E, Mambou Nouemssi JP, Ryder RW. Cancer care challenges in developing countries. Cancer. 2012;118:3627-35.

11. Anderson BO, Yip CH, Smith RA, Shyyan R, Sener SF, Eniu A, et al. Guideline implementation for breast healthcare in low-income and middle-income countries: overview of the breast health global initiative global summit 2007. Cancer. 2008:2221-43.

12. Kanchanachitra $C$, Lindelow $M$, Johnston $T$, Hanvoravongchai $P$, Lorenzo FM, Huong NL, et al. Human resources for health in southeast Asia: shortages, distributional challenges, and international trade in health services. Lancet. 2011:377:769-81.

13. Kösters JP, Gøtzsche PC. Regular self-examination or clinical examination for early detection of breast cancer. In: Kösters JP, editor Cochrane Database Syst Rev Chichester, UK: John Wiley \& Sons, Ltd; 2003;(2):CD003373.

14. Smith RA, Cokkinides V, Brawley OW. Cancer screening in the United States, 2009: a review of current American Cancer Society guidelines and issues in cancer screening. CA Cancer JClin. 2009;59:27-41.

15. Strauss J, Witoelar F, Bondan S. The fifth wave of the Indonesia family life survey: overview and field report. RAND. 2016.

16. Venkataraman $\mathrm{K}$, Wee HL, Ng SHX, Rebello S, Tai ES, Lee J, et al. Determinants of individuals' participation in integrated chronic disease screening in Singapore. J Epidemiol Community Health. 2016;70:1242-50.

17. Sujarwoto S, Tampubolon G. Inflammatory markers and physical performance in middle-aged and older people in Indonesia. Age Ageing 2015;26:1-6.

18. Ford ES. Does exercise reduce inflammation? Physical activity and C-reactive protein among U.S. adults. Epidemiology. 2002;13:561-8.

19. Andresen EM, Byers K, Friary J, Kosloski K, Montgomery R. Performance of the 10-item Center for Epidemiologic Studies Depression scale for caregiving research. SAGE Open Med. 2013:1:205031211351457.

20. Badan Penyelenggara Jaminan Sosial BPJS Kesehatan 2014. Early detection in Cervical Cancer. Available: https://www.bpjs-kesehatan.go.id/bpjs/index. php/post/read/2014/262/Jangan-Khawatir-BPJS-Kesehatan-MenjaminDeteksi-Sebelum-Kanker-Serviks-Menyerang/berita.

21. Razavi L. Indonesia's universal health scheme: one year on, what's the verdict? [Internet]. Guard. 2015. Available from: https://www.theguardian. com/global-development-professionals-network/2015/may/15/indonesiasuniversal-healthcare-insurance-verdict

22. Diaz A, Kang J, Moore SP, Baade P, Langbecker D, Condon JR, et al. Association between comorbidity and participation in breast and cervical cancer screening: a systematic review and meta-analysis. Cancer Epidemiol. 2017:47:7-19.
23. Olson B, Gribble B, Dias J, Curryer C, Vo K, Kowal P, et al. Cervical cancer screening programs and guidelines in low- and middle-income countries. Int J Gynecol Obstet. 2016;134:239-46.

24. Sancho-Garnier H, Khazraji YC, Cherif MH, Mahnane A, Hsairi M, El SA, et al. Overview of cervical cancer screening practices in the extended Middle East and North Africa countries. Vaccine. 2013;31(Suppl 6):G51-7.

25. Sankaranarayanan R, Budukh AM, Rajkumar R. Effective screening programmes for cervical cancer in low- and middle-income developing countries. Bull World Health Organ. 2001:954-62.

26. Denny L, Anorlu R. Cervical cancer in Africa. Cancer Epidemiol Biomark Prev. 2012;21:1434-8.

27. Pathology G. For cervical cancer screening Programme guidelines for cervical cancer screening Programme recommendations of the expert group mee. Cancer. 2006;

28. Aswathy S, Quereshi MA, Kurian B, Leelamoni K. Cervical cancer screening: current knowledge \& practice among women in a rural population of Kerala, India. Indian J Med Res. 2012;136:205-10.

29. Kementerian Kesehatan RI. Center for Epidemiologic Studies: Breast and Cervical Cancer. 2011.

30. Denny L, de Sanjose S, Mutebi M, Anderson BO, Kim J, Jeronimo J, et al. Interventions to close the divide for women with breast and cervical cancer between low-income and middle-income countries and high-income countries. Lancet Elsevier Ltd. 2016;6736:21-30.

31. Sreedevi A, Javed R, Dinesh A. Epidemiology of cervical cancer with special focus on India. Int J Womens Health. 2015;7:405-14.

32. Kim YM, Lambe FM, Soetikno D, Ati A, Lu R. Preventing cervical cancer in karawang district, indonesia: evaluation of 5-year project. Int J Gynecol Obstet. 2012:119:S391.

33. Aggarwal A, Freund K, Sato A, Adams-Campbell LL, Lopez AM, Lessin LS, et al. Are depressive symptoms associated with cancer screening and cancer stage at diagnosis among postmenopausal women? The Women's health initiative observational cohort. J Women's Health (Larchmt). 2008;17:1353-61.

34. O'Donnell S, Goldstein B, MR D, SA F, CR J, JE O. Adherence to mammography and colorectal cancer screening in women 50-80 years of age: The Role of Psychological Distress. Women's Heal Issues. 2010;20:343-9.

35. Lorant V. Socioeconomic inequalities in depression: a meta-analysis. Am J Epidemiol. 2003:157:98-112.

36. Neeme M, Aavik A, Aavik T, Punab M. Personality and utilization of prostate cancer testing. SAGE Open. 2015:5:215824401559332.

37. Gale CR, Deary IJ, Wardle J, Zaninotto P, Batty GD. Cognitive ability and personality as predictors of participation in a national colorectal cancer screening programme: the English longitudinal study of ageing. J Epidemiol Community Health. 2015;69:530-5.

38. Mortel M, Rauscher GH, Murphy AM, Hoskins K, Warnecke RB. Racial and ethnic disparity in symptomatic breast cancer awareness despite a recent screen: the role of tumor biology and mammography facility characteristics. Cancer Epidemiol Biomark Prev. 2015;24:1599-606.

39. Akinyemiju TF. Socio-economic and health access determinants of breast and cervical cancer screening in low-income countries: analysis of the World Health Survey. PLoS ONE [Electronic Resour. 2012;7:e48834.

40. Robb K, Stubbings S, Ramirez A, Macleod U, Austoker J, Waller J, et al. Public awareness of cancer in Britain: a population-based survey of adults. Br J Cancer. 2009;101:S18-S23.

41. Rothman K. No adjustments needed for multiple comparisons. Epidemiology. 1990;1:43-6.

42. World Bank. Population age 65 and above in Indonesia. 2017. Available from: https://data.worldbank.org/indicator/SP.POP.65UP.TO.ZS?end= 2016\&locations=ID\&name_desc=false \&start=1960\&view=chart. 